\title{
Interferon- $\lambda 1$ induces G1 phase cell cycle arrest and apoptosis in gastric carcinoma cells in vitro
}

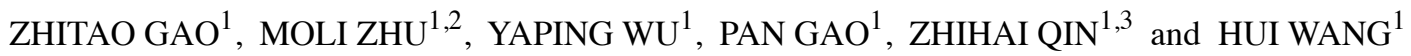 \\ ${ }^{1}$ Research Center for Immunology and ${ }^{2}$ College of Pharmacy, Xinxiang Medical University, Xinxiang, Henan 453003; \\ ${ }^{3}$ Institute of Biophysics, Chinese Academy of Sciences, Beijing 100101, P.R. China
}

Received March 12, 2014; Accepted April 30, 2014

DOI: 10.3892/or.2014.3185

\begin{abstract}
The aim of the present study was to examine the potential antitumor action of IFN- $\lambda 1$ in human gastric carcinoma cell lines and the possible interaction between IFN- $\lambda 1$ and human gastric carcinoma cells. Gastric carcinoma HGC-27 and SGC-7901 cells were treated with IFN- $\lambda 1(0,10$, $100,1000 \mathrm{ng} / \mathrm{ml}$ ) for $48 \mathrm{~h}$. Cytotoxicity was examined using an MTT method. Cell cycle distribution was examined using propidium iodide staining. Apoptosis was examined using the Annexin V-FITC/PI apoptosis kit. By using flow cytometry and JC-1 probe, the mitochondrial membrane potential of cells following treatment with IFN- $\lambda 1$ was also examined. Expression levels of representative apoptosis-related proteins were evaluated by western blot analysis. IFN- $\lambda 1$ inhibited the proliferation of gastric carcinoma cells in a concentration-dependent manner. IFN- $\lambda 1$ increased the accumulation of cells in the sub-G0 phase and arrested the cells in the G1 phase. Exposure to IFN- $\lambda 1$ decreased the mitochondrial membrane potential and increased apoptosis. Moreover, IFN- $\lambda 1$ exposure upregulated the expression of p21,p27 and Bax, downregulated the expression of Bcl-2, increased the release of cytochrome $c$ and apoptosis-inducing factor (AIF) and activated caspase- 3 and caspase-9. In conclusion, IFN- $\lambda 1$ inhibits the proliferation of gastric carcinoma cells by arresting the cells in the G1 phase and by inducing mitochondrial-mediated apoptosis.
\end{abstract}

\section{Introduction}

Interferon- $\lambda$ (IFN- $\lambda$ ), type III IFNs, the newest IFN family, includes 3 subtypes, IFN- $\lambda 1,-\lambda 2$ and $-\lambda 3$, also known as interleukin-29 (IL-29), IL-28A and IL-28B. All of the IFN- $\lambda$ s bind the same heterodimeric receptor complexes composed of the IL-10 receptor $\beta$ (IL-10R $\beta$ ) and a novel IL-28 receptor $\alpha$

Correspondence to: Professor Hui Wang or Professor Zhihai Qin, Research Center for Immunology, Xinxiang Medical University, Jinsui Road, Xinxiang, Henan 453003, P.R. China

E-mail: wanghui@xxmu.edu.cn

E-mail: 404920661@qq.com

Key words: interferon- $\lambda 1$, gastric carcinoma, G1 cell cycle arrest, apoptosis
(IL-28R $\alpha$ ) $(1,2)$. Interferons (IFNs) have been described as agents mediating antiviral responses for many years. Type I IFNs, IFN- $\alpha / \beta$, have been clinically applied for treating certain types of malignancies for more than 30 years, yet a wide range of adverse effects hampered further clinical applications $(3,4)$. However, further investigations are required to clarify the biological properties and the mechanisms responsible for their functions. Type III IFNs, IFN- $\lambda s$, have similar signaling pathways as IFN- $\alpha / \beta$ and inhibit the proliferation of tumor cells through cell cycle arrest or apoptosis.

Gastric carcinoma is an intractable disease, with a high incidence and mortality rate, as it frequently develops in the aged (5-7). Extensive surgery decreases the quality of life of patients, and radical chemotherapy and radiotherapy are not often appropriate for aged patients (8). A novel therapeutic strategy is thereby required to improve prognosis. More effective, preventive and therapeutic approaches are urgently needed. Type I IFNs have been clinically examined in various types of malignanies including gastric carcinoma. Yet, type I IFNs are associated with numerous serious adverse effects, e.g. major depression. Type III IFNs have various immunological actions similar to type I IFNs. However, IFN- $\lambda$-mediated growth suppression has not yet been well explored.

Research has shown that the IFN- $\lambda$ s may have unique cellular functions distinct from their role as secreted cytokines (9). Yan et al found that the IFN- $\lambda$ s could inhibit lung carcinoma cell growth and produce antitumor effects (10). The same observation was also made by Steen et al that IFN- $\lambda \mathrm{s}$ could sharply inhibit the proliferation of gastric carcinoma cells (11). These results indicate that IFN- $\lambda$ s may be a new therapeutic option for tumors. However, whether IFN- $\lambda$ s inhibit the growth of gastric carcinoma cells remains unknown.

In the present study, we examined the potential antitumor action of IFN- $\lambda 1$ in human gastric carcinoma cell lines and the possible interaction between IFN- $\lambda 1$ and human gastric carcinoma cells. The results indicated that IFN- $\lambda 1$ plays a crucial role in inhibiting gastric carcinoma cells and provide the foundation for the use of IFN- $\lambda 1$ in tumor therapy.

\section{Materials and methods}

Antibodies and reagents. Mouse anti-human monoclonal primary antibodies for $\beta$-actin, Bax, cytochrome $c$, apoptosis-inducing factor (AIF), p21, p27 and horseradish 
peroxidase-conjugated goat anti-mouse IgG antibodies were purchased from Cell Signaling (Beverly, MA, USA). RPMI-1640 and fetal bovine serum (FBS) were purchased from Gibco (Invitrogen, USA). Propidium iodide (PI) was purchased from Sigma-Aldrich (St. Louis, MO, USA). IFN- $\lambda 1$ was purchased from R\&D Systems (Minneapolis, MN, USA). Viable cells were measured with a cell proliferation assay kit [3-(4,5-dimethylthiazol-2-yl)-2,5-diphenyltetrazolium bromide; MTT] (Roche, USA). The Annexin V-FITC/PI apoptosis kit was purchased from Biosea Biotechnology Co. Ltd. (Beijing, China). All other reagents were purchased from Sigma-Aldrich unless otherwise mentioned.

Cell culture. Human gastric carcinoma HGC-27 and SGC-7901 cells were obtained from the Chinese Type Culture Collection (Institute of Cell Biology, Chinese Academy of Science, Shanghai, China) and cultured in RPMI-1640 medium containing $10 \% \mathrm{FBS}, 100 \mathrm{IU} / \mathrm{ml}$ penicillin and 100 $\mathrm{mg} / \mathrm{ml}$ streptomycin at $37^{\circ} \mathrm{C}$ in a humidified atmosphere of $5 \% \mathrm{CO}_{2}$ and $95 \%$ air. After reaching $80-90 \%$ confluency, cells were collected by $0.25 \%$ trypsin detachment and centrifugation and then replanted into 96- or 6-well plates at an appropriate density according to the different experimental requirements. After a 48-h culture, all experiments were performed.

Cell viability assay. Cell viability was evaluated using the MTT assay. Cells were seeded in a 96-well plate at a density of $5 \times 10^{3}$ cells/well. The total volume was adjusted to $200 \mu \mathrm{l}$ with growth medium. At $24 \mathrm{~h}$ after the seeding, cells were treated with different concentrations of IFN- $\lambda 1(0,10,100$, $1000 \mathrm{ng} / \mathrm{ml})$. Cell viability was examined after $48 \mathrm{~h}$ using a standard MTT method. Drug effect was expressed as a percentage relative to the controls. The rate of cell viability was calculated as follows: (absorbance of treated group absorbance of blanks)/(absorbance of control - absorbance of blanks) x 100 expressed as a percentage.

Flow cytometry and cell cycle analysis. The apoptotic cells were detected using the Annexin V-FITC apoptosis kit. Briefly, the treated cells were collected by $0.25 \%$ trypsin and centrifuged, then washed with ice-cold phosphate buffer solution and resuspended in $200 \mu \mathrm{l}$ binding buffer at a density of $1 \times 10^{6} / \mathrm{ml}$. Ten microliters of Annexin V-FITC antibody was added, and cells were incubated for $30 \mathrm{~min}$ at room temperature and supplemental $300 \mu \mathrm{l}$ of binding buffer was added and cells were stained with $5 \mu \mathrm{l}$ PI for $5 \mathrm{~min}$. The apoptotic cells were measured by flow cytometry (FACScan, BectonDickinson, Mountain View, CA, USA). For synchronization at $\mathrm{G} 1$ phase, cells were cultured with IFN- $\lambda 1$ and fixed in icecold $70 \%$ ethanol, treated with RNase $(50 \mu \mathrm{g} / \mathrm{ml})$ and stained with PI $(50 \mu \mathrm{g} / \mathrm{ml})$. Cell cycle distribution was analyzed with FACScan and Cell Quest software.

Detection of mitochondrial membrane potential $\left(\Delta \Psi_{m}\right)$. The mitochondrial membrane potential $\Delta \Psi_{\mathrm{m}}$ was determined using the KeyGEN mitochondrial membrane JC-1 kit (KeyGEN, China) according to the manufacturer's instructions (12). Briefly, after cells were infected with viral particles for the indicated times, the cells were pelleted, washed with PBS and resuspended in $0.5 \mathrm{ml}$ of diluted $\mathrm{JC}-1$ reagent $(1 \mu \mathrm{mol} / \mathrm{ml}$ in incubation buffer) for $20 \mathrm{~min}$. Then $0.2 \mathrm{ml}$ of incubation buffer was added, and the cells were centrifuged, washed and resuspended in $1 \mathrm{ml}$ PBS for laser scanning confocal microscopy (Olympus, Japan) and flow cytometry.

Western blot analysis. Cells were treated with IFN- $\lambda 1$ for $48 \mathrm{~h}$ and washed with phosphate-buffered saline and then resuspended in RIPA buffer $(25 \mathrm{mM}$ Tris- $\mathrm{HCl}, \mathrm{pH} 7.6$, $150 \mathrm{mM} \mathrm{NaCl}, 1 \%$ Nonidet P-40, $1 \%$ sodium deoxycholate, $0.1 \%$ SDS) with a protease inhibitor cocktail (Sigma-Aldrich). SDS-PAGE was performed with $12 \%$ polyacrylamide gels, and portions $(25 \mu \mathrm{g})$ of protein of the cell lysate were used. After electrotransfer, membranes were blocked for $1 \mathrm{~h}$ at room temperature with 6\% Quick-Blocker (Chemicon, Temecula, CA, USA) dissolved in TBST [20 mM Tris- $\mathrm{HCl}, 137 \mathrm{mM}$ $\mathrm{NaCl}, 0.1 \%$ (v/v) Tween-20, pH 7.6], then incubated overnight at $4{ }^{\circ} \mathrm{C}$ with the different primary antibodies at the appropriate dilution in TBS-T buffer. The following monoclonal antibodies were used: anti-p21 antibody (Ab), anti-p27 Ab, anti-Bax Ab, anti-Bcl-2 Ab, anti-caspase-3 Ab, anti-caspase-9 $\mathrm{Ab}$, anti-cytochrome $c \mathrm{Ab}$ and anti-apoptosis-inducing factor (AIF) Ab (Cell Signaling, Beverly, MA, USA), followed by incubation with a horseradish peroxidase-conjugated secondary antibody. The membranes were developed with the ECL system (GE Healthcare, Little Chalfont, UK) and exposed to X-ray film. The anti- $\beta$-actin antibody was used as an internal control for sample loading.

Statistical analysis. The results from the in vivo studies are representative of at least 2-3 independent experiments and are expressed as mean \pm SD. The differences between the groups were examined using one-way analysis of variance (ANOVA) using the Statistical Package for the Social Sciences (SPSS) 14.0 software (SPSS Inc., Chicago, IL, USA). Statistical significance was assumed at $\mathrm{P}<0.05$ in all cases.

\section{Results}

IFN- $\lambda 1$-mediated growth suppression. We examined whether IFN $-\lambda 1$ could suppress the growth of the gastric carcinoma cells. We treated the HGC-27 and SGC-7901 cells with IFN- $\lambda 1$ and examined the viability and the cell proliferation rates. Compared with the control group, IFN- $\lambda 1$ treatment significantly inhibited the proliferation of the gastric carcinoma cells in a concentration-dependent manner (Fig. 1).

G1 phase arrest induced by IFN- $\lambda 1$. To explain the mechanism of cell growth inhibition by IFN- $\lambda 1$ concerning cell cycle change, we analyzed the effects of IFN- $\lambda 1$ treatment on the cell cycle. As shown in Table I, the percentage of cells in the G1 phase increased, whereas the percentage of cells in the G2 and $\mathrm{S}$ phases decreased (Fig. 2). These results demonstrated that IFN- $\lambda 1$ induced G1 phase arrest in the gastric carcinoma cells.

Mitochondrial membrane potential $\Delta \Psi m$. To confirm the effects of IFN- $\lambda 1$ on gastric carcinoma cell mitochondria in vitro, gastric carcinoma cells were treated with different concentrations of IFN- $\lambda 1$. Changes in mitochondrial membrane 
A

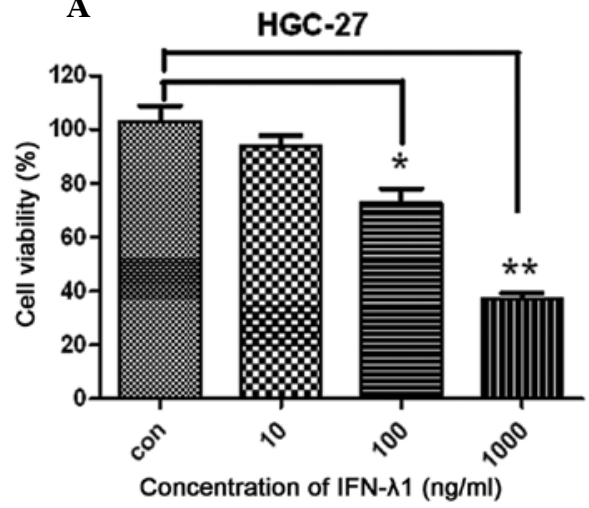

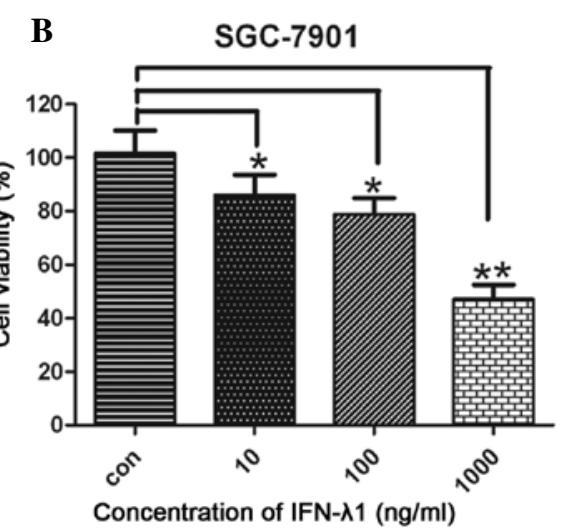

Figure 1. IFN- $\lambda 1$ inhibits cell proliferation in the HGC-27 and SGC-7901 cells. (A) HGC-27 and (B) SGC-7901 cells were incubated with the indicated concentrations of IFN- $\lambda 1$ for $48 \mathrm{~h}$, and cell proliferation was determined by the MTT assay. The values shown are the mean \pm SD from five replicated wells for each treatment and are expressed as a percentage of the control cells. Significance of the differences to the control cells was analyzed using one-way ANOVA $\left({ }^{*} \mathrm{P}<0.05 ;{ }^{* *} \mathrm{P}<0.01\right)$. IFN- $\lambda 1$, interferon- $\lambda 1$.
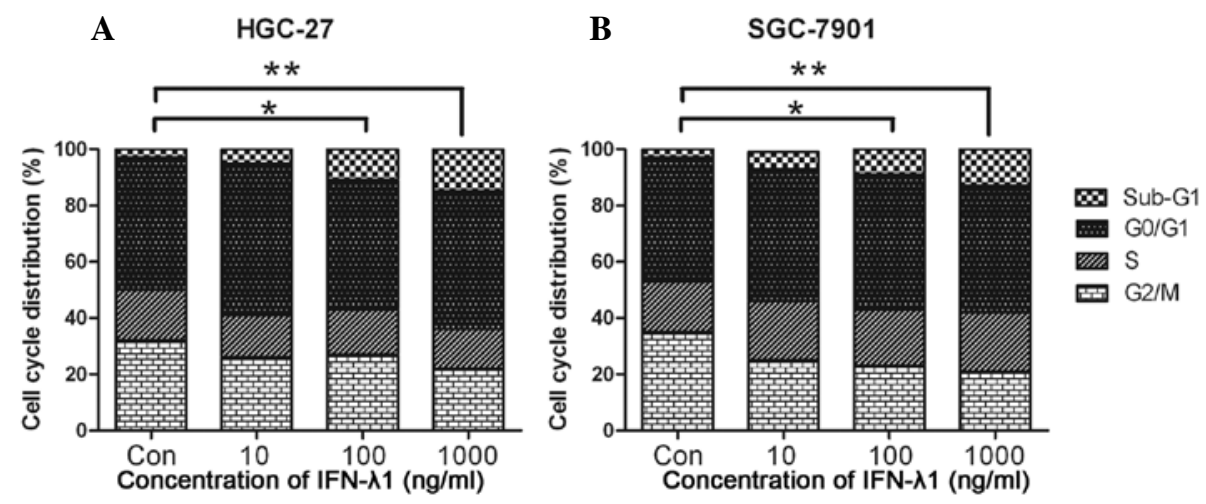

Figure 2. Cells were infected with the indicated concentrations of IFN- $\lambda 1$ and cultured for $48 \mathrm{~h}$. Cell cycle profiles of (A) HGC-27 and (B) SGC-7901 cells were analyzed using flow cytometry, and the data are shown in mean percentages with s.e.s $(\mathrm{n}=3)$. ${ }^{*} \mathrm{P}<0.05,{ }^{* *} \mathrm{P}<0.01$, comparison between IFN- $\lambda 1$-treated and control cells. IFN- $\lambda 1$, interferon- $\lambda 1$.

Table I. Cell cycle distribution after Ad/IFN- $\lambda 1$ treatment.

\begin{tabular}{|c|c|c|c|c|c|}
\hline \multirow[b]{2}{*}{ Cells } & \multirow{2}{*}{$\begin{array}{l}\text { Treatment } \\
(\mathrm{ng} / \mathrm{ml})\end{array}$} & \multicolumn{4}{|c|}{ Cell cycle distribution (\%) } \\
\hline & & Sub-G1 & G0/G1 & $\mathrm{S}$ & $\mathrm{G} 2 / \mathrm{M}$ \\
\hline \multirow[t]{4}{*}{ HGC-27 } & Control & $2.7 \pm 0.7$ & $47.5 \pm 1.4$ & $17.6 \pm 0.7$ & $33.7 \pm 0.9$ \\
\hline & 10 & $4.9 \pm 0.9$ & $53.7 \pm 1.2^{\mathrm{a}}$ & $15.2 \pm 0.3$ & $28.1 \pm 0.8$ \\
\hline & 100 & $11.0 \pm 0.3^{\mathrm{a}}$ & $46.1 \pm 0.8$ & $15.9 \pm 0.2$ & $27.1 \pm 1.2$ \\
\hline & 1000 & $15.3 \pm 0.7^{b}$ & $49.2 \pm 0.4$ & $14.7 \pm 0.1$ & $23.2 \pm 0.9$ \\
\hline \multirow[t]{4}{*}{ SGC-7901 } & Control & $3.1 \pm 0.8$ & $44.0 \pm 0.3$ & $18.3 \pm 0.6$ & $34.6 \pm 0.6$ \\
\hline & 10 & $5.6 \pm 0.6$ & $47.5 \pm 0.9$ & $20.9 \pm 1.4$ & $26.5 \pm 0.7$ \\
\hline & 100 & $8.9 \pm 0.9^{\mathrm{a}}$ & $48.8 \pm 0.6$ & $20.1 \pm 0.2$ & $22.9 \pm 1.2$ \\
\hline & 1000 & $13.4 \pm 0.4^{\mathrm{b}}$ & $45.1 \pm 0.7$ & $21.3 \pm 1.0$ & $22.1 \pm 0.8$ \\
\hline
\end{tabular}

${ }^{\mathrm{a}} \mathrm{P}<0.05,{ }^{\mathrm{b}} \mathrm{P}<0.01$, comparison between IFN- $\lambda 1$-treated and control cells

potential of the cells were detected using laser scanning confocal microscopy (Fig. 3A and 3B) and flow cytometry (Fig. 3C). It was obvious that the mitochondrial membrane potential was decreased after treatment with IFN- $\lambda 1$ (Fig. 3D). Based on the results above, we hypothesized that IFN- $\lambda 1$ may induce apoptosis through pathways that downregulate mitochondrial membrane potential.

Apoptosis induction by IFN- $\lambda 1$ treatment. Apoptosis was confirmed by Annexin V and PI staining. As shown in Fig 4, 


\section{A $\mathrm{HGC}-27$}

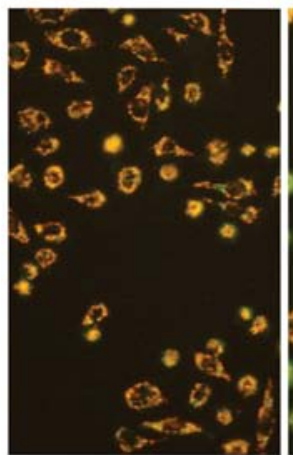

Con

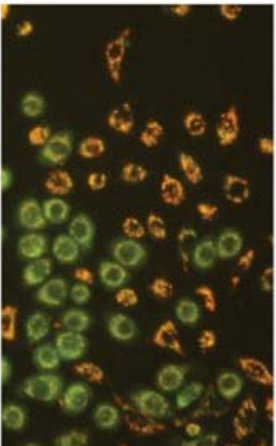

$10 \mathrm{ng} / \mathrm{ml}$

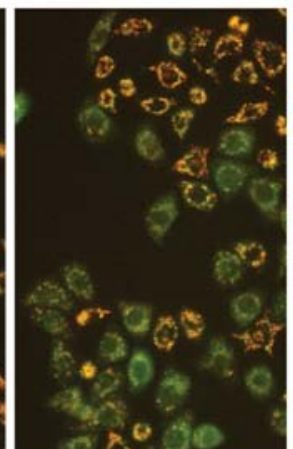

$100 \mathrm{ng} / \mathrm{ml}$

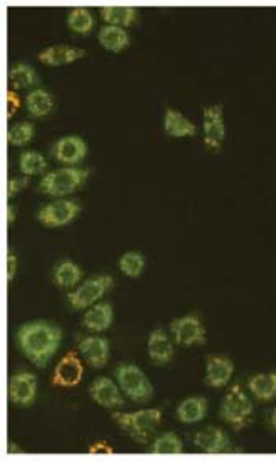

$1000 \mathrm{ng} / \mathrm{ml}$

\section{B SGC-7901}

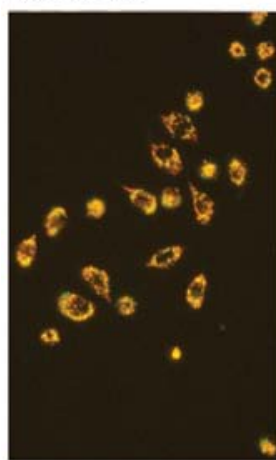

Con

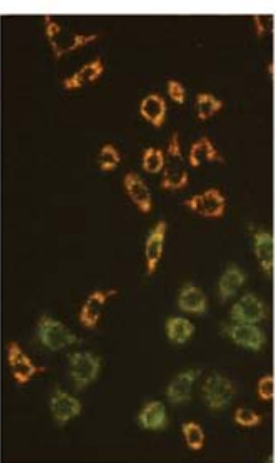

$10 \mathrm{ng} / \mathrm{ml}$

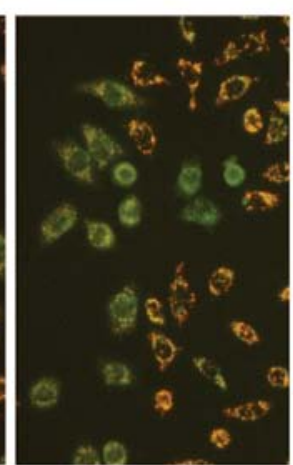

$100 \mathrm{ng} / \mathrm{ml}$

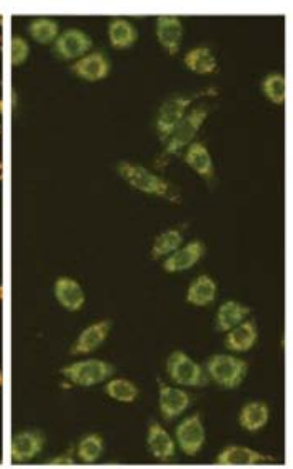

$1000 \mathrm{ng} / \mathrm{ml}$

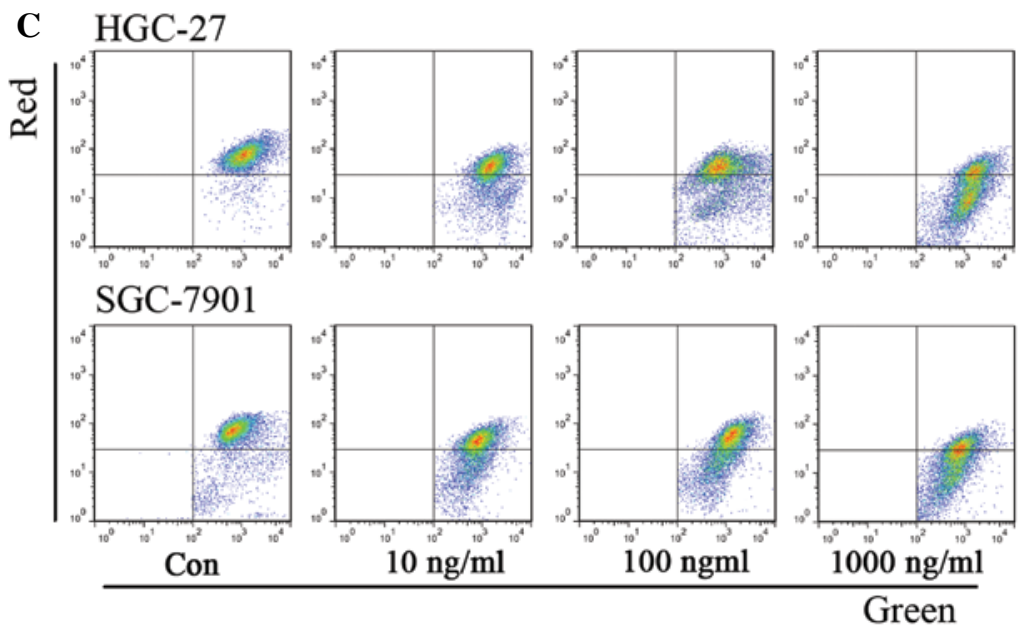

D

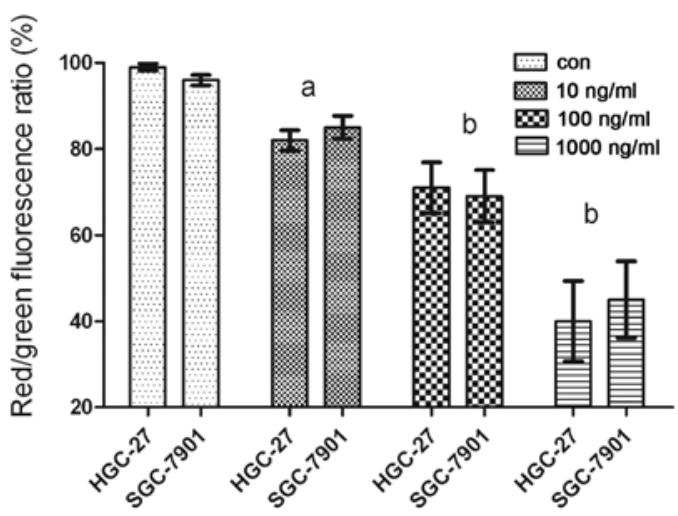

Figure 3. Measurement of mitochondrial membrane potential (MMP) was determined using JC-1 probe. JC-1 is widely used to monitor mitochondrial membrane depolarization. (A and B) In the IFN- $\lambda 1$ untreated cells (Con) with high mitochondrial membrane potential, JC-1 spontaneously formed complexes known as J-aggregates with intense red fluorescence. Whereas, in the IFN- $\lambda 1$-treated or apoptotic cells with low mitochondrial membrane potential, JC-1 remained in the monomeric form, which shows only green fluorescence. Thus mitochondrial depolarization was indicated by a decrease in red/green fluorescence intensity ratio. (C) Flow cytometric analysis of mitochondrial membrane potential in the HGC-27 and SGC-7901 cells. (D) Data are expressed as mean \pm SEM ( $=3$ ). Columns not sharing the same superscripted letter differ significantly; ${ }^{a} \mathrm{P}<0.05$ and ${ }^{\mathrm{b}} \mathrm{P}<0.01$. IFN- $\lambda 1$, interferon- $\lambda 1$.

the Annexin $\mathrm{V}^{+} / \mathrm{PI}$ fraction and subsequently the Annexin $\mathrm{V}^{+} / \mathrm{PI}^{+}$fraction of the gastric carcinoma cells were increased following IFN- $\lambda 1$ treatment. These data collectively suggest an apoptotic effect of IFN- $\lambda 1$ in gastric carcinoma cells.

Expression of proteins involved in cell cycle progression and apoptosis. To understand the mechanism by which IFN- $\lambda 1$ caused G1-phase cell cycle arrest, we examined the effects of
IFN- $\lambda 1$ on the induction of $\mathrm{p} 21$ and $\mathrm{p} 27$, which regulate the G1-phase checkpoint (13-15). IFN- $\lambda 1$ treatment induced p21 and p27 expression in a concentration-dependent manner $(\mathrm{P}<0.05)$ (Fig. 5), suggesting that IFN- $\lambda 1$ may regulate cell cycle arrest through p21 and p27.

Disruption of the mitochondrial membrane potential is a critical event in triggering mitochondrial-mediated apoptosis. Mitochondrial dysfunction is induced by various cellular 
A $\quad$ HGC-27
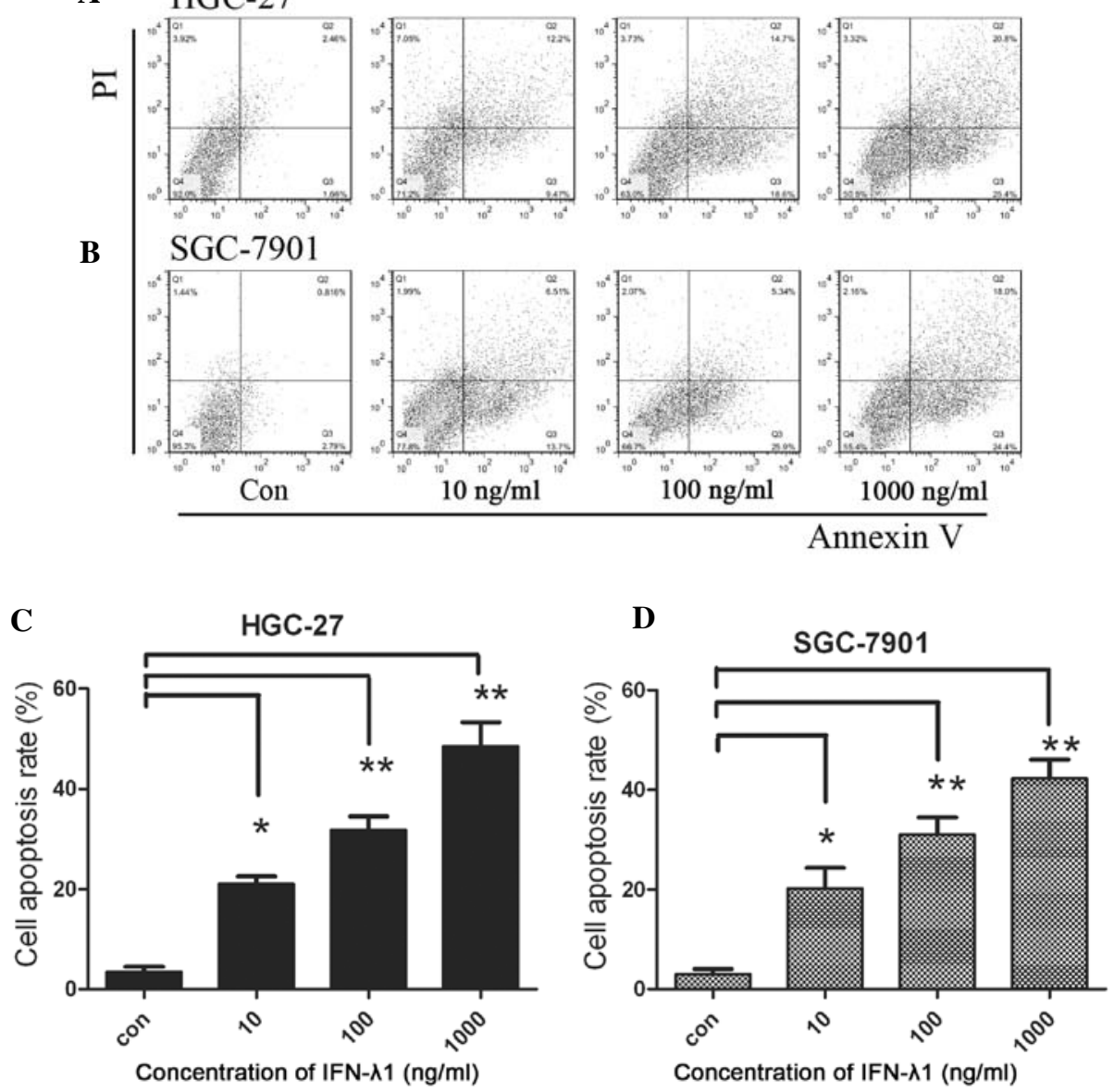

Figure 4. Flow cytometric analysis of apoptosis. (A) HGC-27 and (B) SGC-7901 cells were treated with IFN- $\lambda 1$ for $48 \mathrm{~h}$ or left untreated (Con). (C and D) The cell apoptosis rates were increased in both cell lines in a dose-dependent manner. Data are expressed as mean \pm SEM $(n=3)$. $\left({ }^{*} \mathrm{P}<0.05{ }^{* * *} \mathrm{P}<0.01\right)$.

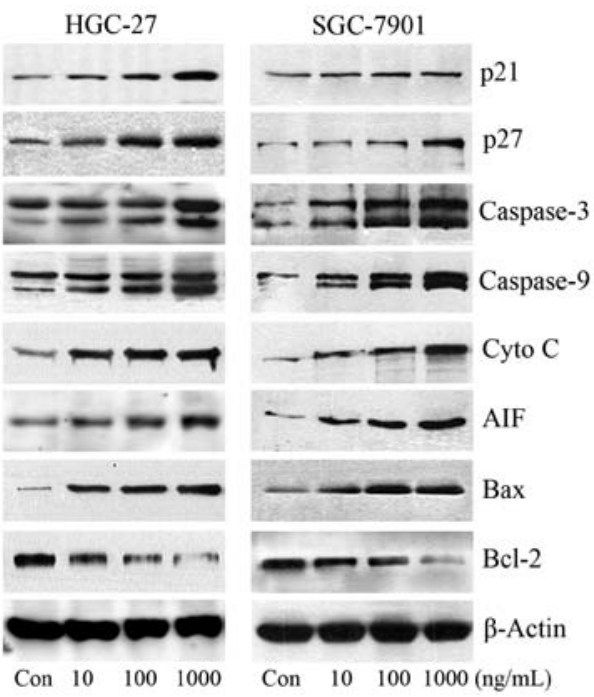

Figure 5. Expression levels of apoptosis-linked proteins in the HGC-27 and SGC-7901 cells following IFN- $\lambda 1$ treatment for $48 \mathrm{~h}$. Expression levels of caspase-3, caspase-9, the respective cleaved forms, Bax, Bcl-2, cytochrome $c$ and AIF in the cytoplasmic fraction were analyzed by western blot analyses. Actin expression is shown as a loading control for total cytoplasmic protein, respectively. IFN- $\lambda 1$, interferon- $\lambda 1$.

stimuli, causing the translocation of Bax from the cytosol to the mitochondria, which subsequently triggers the release of cytochrome $c$ and AIF from the mitochondria into the cytosol and finally induces apoptosis via either caspase-dependent or caspase-independent pathways. To further clarify the mechanisms of apoptosis in the gastric carcinoma cells triggered by IFN- $\lambda 1$, we targeted apoptotic proteins in the mitochondrial pathway. IFN- $\lambda 1$ significantly increased Bax expression in the mitochondria (Fig. 5). IFN- $\lambda 1$ also concentration-dependently upregulated the expression of cytochrome $c$ and AIF proteins $(\mathrm{P}<0.05)$.

\section{Discussion}

In recent years, increasing research has focused on the relationship between cytokines and tumorigenesis. It has been suggested that cytokines may be a new therapeutic option for tumors (16-20). In our experiments, we demonstrated that IFN- $\lambda 1$ inhibited the growth of gastric carcinoma cells in a concentration-dependent manner. These data suggest that IFN- $\lambda 1$ may be a potential antitumor agent for the treatment of gastric cancer.

Impaired apoptotic induction and dysregulated cell cycle progression are important factors in cancer development. Accordingly, inhibition of cell cycle regulation is particularly useful in the treatment of cancer. In our in vitro study, we demonstrated the apoptosis-inducing effects of IFN- $\lambda 1$ in gastric carcinoma cells using PI cell cycle analysis, Annexin V 
and PI staining as well as activated caspase-3. Our study showed that IFN- $\lambda 1$ induced G1 phase arrest and apoptosis in the gastric carcinoma cells.

Experimental evidence suggests that apoptosis can be mediated by several different pathways and that there are numerous regulatory molecules associated with these pathways. Proteins of the Bcl-2 family include both pro- and anti-apoptotic members that elicit opposing effects on mitochondria (21-23) Enhancement of pro-apoptotic Bax over Bcl-2 proteins can enhance the permeability of the mitochondrial membrane, which in turn results in the release of apoptogenic factors. Repression of anti-apoptotic members of this family, including $\mathrm{Bcl}-2$ and $\mathrm{Bcl}-\mathrm{xl}$, preserves the integrity of the mitochondria. This blocks the release of soluble inter-membrane factors such as cytochrome $c$ that activate effectors of apoptosis. In the present study, we found that treatment of gastric carcinoma cells with IFN- $\lambda 1$ upregulated pro-apoptotic Bax protein and downregulated anti-apoptotic protein Bcl-2.

The alteration in the $\mathrm{Bax} / \mathrm{Bcl}-2$ ratio is critical for apoptosis and causes the release of cytochrome $c$ from mitochondria into the cytosol after loss of mitochondrial membrane potential. Cytosolic cytochrome $c$ can bind to Apaf-1 and activate caspase-9 in the apoptosomes in response to diverse inducers of cell death. Caspase-9 is activated and finally an increase in the activation or cleavage of caspase- 3 results $(24,25)$. It has been recognized that control of cell cycle progression in cancer cells is an effective strategy to inhibit tumor growth as the molecular analyses of human cancers have revealed that cell cycle regulators are frequently deregulated in most common malignancies. Our in vitro data demonstrated that treatment of gastric carcinoma cells with IFN- $\lambda 1$ induced G1 phase arrest of cell cycle progression, indicating that one of the mechanisms by which IFN- $\lambda 1$ inhibits the proliferation of gastric cancer cells is inhibition of cell cycle progression.

Regulation of the cell cycle at the G1 checkpoint is complex and involves multiple molecular processes. p21 appears to be important since introduction of nonfunctional p21 or a p21 antisense oligonucleotide diminished the G1 arrest in a variety of cancer cells $(26,27)$. Apart from directly inhibiting cyclin-dependent kinase activity to promote cell cycle arrest, p21 interacts with proliferating cell nuclear antigens. Our results demonstrated elevated p21 and p27 levels in gastric carcinoma cells in response to IFN- $\lambda 1$. It is possible that G1 arrest upon IFN- $\lambda 1$ treatment here was caused by p21 and p27. Exposure to IFN- $\lambda 1$ elevated the Bax level in the mitochondria, and stimulated the release of cytochrome $c$ and AIF from the mitochondria into the cytosol, suggesting that IFN- $\lambda 1$-induced apoptosis in gastric carcinoma cells is mediated by the mitochondrial pathway.

In conclusion, we demonstrated that IFN- $\lambda 1$ induced G1 phase arrest and apoptotic cell death in gastric carcinoma cells through the activation of $\mathrm{p} 21 / \mathrm{p} 27$ and the mitochondrialmediated apoptotic pathway. In the present study, although the exact mechanism remains unclear, IFN- $\lambda 1$ as a chemotherapeutic agent induces cell death and may be a potential therapeutic option for gastric cancers.

\section{References}

1. Lopušná K, Režuchová I, Betáková T, et al: Interferons lambda, new cytokines with antiviral activity. Acta Virol 57: 171-179, 2013.
2. Tagawa M, Kawamura K, Li Q, et al: A possible anticancer agent, type III interferon, activates cell death pathways and produces antitumor effects. Clin Dev Immunol 2011: 479013, 2011.

3. Li Q, Kawamura K, Okamoto S, et al: Adenoviruses-mediated transduction of human oesophageal carcinoma cells with the interferon- $\lambda$ genes produced anti-tumour effects. Br J Cancer 105: 1302-1312, 2011.

4. Donnelly RP and Kotenko SV: Interferon-lambda: a new addition to an old family. J Interferon Cytokine Res 30: 555-564, 2010.

5. Tamura W and Fukami N: Early gastric cancer and dysplasia. Gastrointest Endosc Clin N Am 23: 77-94, 2013.

6. Hu Y, Fang JY and Xiao SD: Can the incidence of gastric cancer be reduced in the new century? J Dig Dis 14: 11-15, 2013.

7. Iravani O, Tay BW, Chua PJ, et al: Claudins and gastric carcinogenesis. Exp Biol Med 238: 344-349, 2013.

8. Saito H, Takaya S, Fukumoto Y, et al: Clinicopathologic characteristics and prognosis of gastric cancer in young patients. Yonago Acta Med 55: 57-61, 2012.

9. Wongthida P, Diaz RM, Galivo F, et al: Type III IFN interleukin-28 mediates the antitumor efficacy of oncolytic virus VSV in immune-competent mouse models of cancer. Cancer Res 70: 4539-4549, 2010.

10. Yan Y, Zhang J, Liu Y, et al: Inhibition of lung adenocarcinoma transfected with interleukin 28A recombinant adenovirus (AdmIFN- $\lambda 2$ ) in vivo. Cancer Biother Radiopharm 28: 124-130, 2013.

11. Steen HC and Gamero AM: Interferon-lambda as a potential therapeutic agent in cancer treatment. J Interferon Cytokine Res 30: 597-602, 2010.

12. Ding F, Shao ZW, Yang SH, et al: Role of mitochondrial pathway in compression-induced apoptosis of nucleus pulposus cells. Apoptosis 17: 579-590, 2012.

13. Mitrea DM, Yoon MK, Ou L, et al: Disorder-function relationships for the cell cycle regulatory proteins p21 and p27. Biol Chem 393: 259-274, 2012.

14. Wang L, Wang G, Yang D, et al: Euphol arrests breast cancer cells at the G1 phase through the modulation of cyclin D1, p21 and p27 expression. Mol Med Rep 8: 1279-1285, 2013.

15. Zhang Z, Du GJ, Wang CZ, et al: Compound K, a ginsenoside metabolite, inhibits colon cancer growth via multiple pathways encluding p53-p21 interactions. Int J Mol Sci 14: 2980-2995, 2013.

16. Abushahba W, Balan M, Castaneda I, et al: Antitumor activity of type I and type III interferons in BNL hepatoma model. Cancer Immunol Immunother 59: 1059-1071, 2010.

17. Yang L, Wei $J$ and He S: Integrative genomic analyses on interferon-lambdas and their roles in cancer prediction. Int J Mol Med 25: 299-304, 2010.

18. Li Q, Kawamura K, Ma G, et al: Interferon-lambda induces G1 phase arrest or apoptosis in oesophageal carcinoma cells and produces anti-tumour effects in combination with anti-cancer agents. Eur J Cancer 46: 180-190, 2010.

19. Lasfar A, Abushahba W, Balan M, et al: Interferon lambda: a new sword in cancer immunotherapy. Clin Dev Immunol 2011: 349575, 2011.

20. George PM, Badiger R, Alazawi W, et al: Pharmacology and therapeutic potential of interferons. Pharmacol Ther 135: 44-53, 2012.

21. Renault TT, Teijido O, Antonsson B, et al: Regulation of Bax mitochondrial localization by Bcl-2 and Bcl-x (L): keep your friends close but your enemies closer. Int J Biochem Cell Biol 45: 64-67, 2013.

22. Low IC, Kang J and Pervaiz S: Bcl-2: a prime regulator of mitochondrial redox metabolism in cancer cells. Antioxid Redox Signal 15: 2975-2987, 2011.

23. Shamas-Din A, Kale J, Leber B, et al: Mechanisms of action of Bcl-2 family proteins. Cold Spring Harb Perspect Biol 5: a008714, 2013.

24. Imesch P, Scheiner D, Szabo E, et al: Conjugates of cytochrome $c$ and antennapedia peptide activates apoptosis and inhibit proliferation of HeLa cancer cells. Exp Ther Med 6: 786-790, 2013.

25. Liang J, Yu Y, Wang B, et al: Ginsenoside Rb1 attenuates oxygen-glucose deprivation-induced apoptosis in SH-SY5Y cells via protection of mitochondria and inhibition of AIF and cytochrome $c$ release. Molecules 18: 12777-12792, 2013.

26. Park C, Jeong NY, Kim GY, et al: Momilactone B induces apoptosis and G1 arrest of the cell cycle in human monocytic leukemia U937 cells through downregulation of pRB phosphorylation and induction of the cyclin-dependent kinase inhibitor p21Waf1/Cip1. Oncol Rep 31: 1653-1660, 2014.

27. Koyama M, Sowa Y, Hitomi T, et al: Perillyl alcohol causes G1 arrest through p15(INK4b) and p21(WAF1/Cip1) induction. Oncol Rep 29: 779-784, 2013. 